
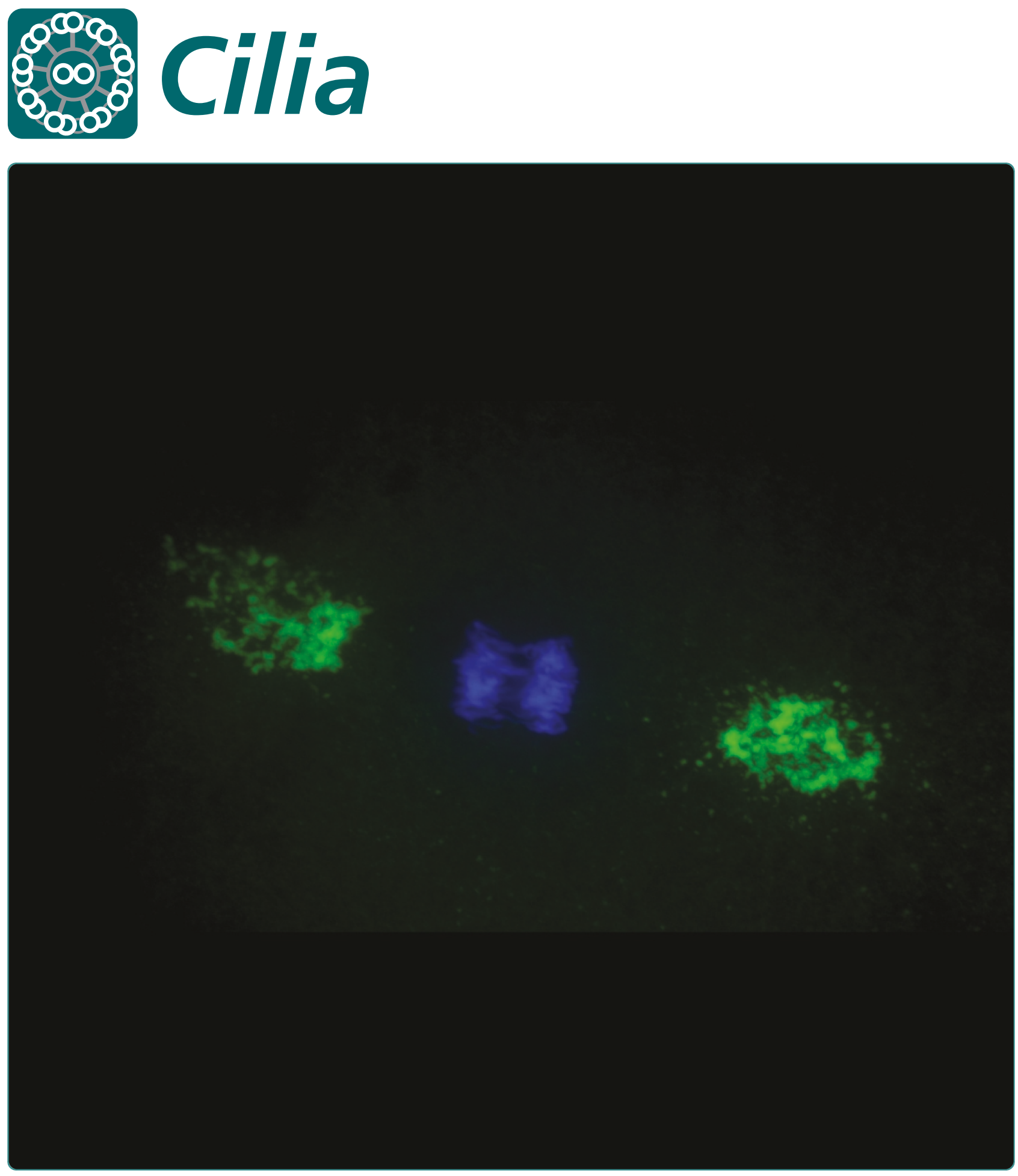

Centrosomes in the zebrafish (Danio rerio): a review including the related basal body

Lessman 


\title{
Centrosomes in the zebrafish (Danio rerio): a review including the related basal body
}

\author{
Charles A Lessman
}

\begin{abstract}
Ever since Edouard Van Beneden and Theodor Boveri first formally described the centrosome in the late 1800s, it has captivated cell biologists. The name clearly indicated its central importance to cell functioning, even to these early investigators. We now know of its role as a major microtubule-organizing center (MTOC) and of its dynamic roles in cell division, vesicle trafficking and for its relative, the basal body, ciliogenesis. While centrosomes are found in most animal cells, notably it is absent in most oocytes and higher plant cells. Nevertheless, it appears that critical components of the centrosome act as MTOCs in these cells as well. The zebrafish has emerged as an exciting and promising new model organism, primarily due to the pioneering efforts of George Streisinger to use zebrafish in genetic studies and due to Christiane Nusslein-Volhard, Wolfgang Driever and their teams of collaborators, who applied forward genetics to elicit a large number of mutant lines. The transparency and rapid external development of the embryo allow for experiments not easily done in other vertebrates. The ease of producing transgenic lines, often with the use of fluorescent reporters, and gene knockdowns with antisense morpholinos further contributes to the appeal of the model as an experimental system. The added advantage of high-

throughput screening of small-molecule libraries, as well as the ease of mass rearing together with low cost, makes the zebrafish a true frontrunner as a model vertebrate organism. The zebrafish has a body plan shared by all vertebrates, including humans. This conservation of body plan provides added significance to the existing lines of zebrafish as human disease models and adds an impetus to the ongoing efforts to develop new models. In this review, the current state of knowledge about the centrosome in the zebrafish model is explored. Also, studies on the related basal body in zebrafish and their relationship to ciliogenesis are reviewed.
\end{abstract}

Keywords: $\gamma$-tubulin, spindle, cilium, centriole, centrin, microtubule, MTOC

\section{Introduction}

According to EB Wilson in his classic text, The Cell in Development and Heredity [1], Van Beneden first described the "polar corpuscle" in 1876 and Boveri later named it the "centrosome" in 1888. For more than a century, the centrosome has intrigued scientists and continues to do so today. Although much is now known about the centrosome, it remains somewhat mysterious, with many secrets left to reveal about its function and regulation. The zebrafish (Danio rerio), a small tropical freshwater teleost, has emerged as a model for cell and developmental biology because of its high fecundity, short generation time and rapid development of the externally fertilized and translucent embryos [2] (see

Correspondence: Clessman@memphis.edu

Department of Biological Sciences, The University of Memphis, Life Sciences 223, Memphis, TN 38152, USA also [3]). As a relatively new model organism, the zebrafish has attracted considerable attention in the scientific community due to its genetic tractability, speed of embryonic development and optical clarity. Many scientists espouse the hope that the advantages of the zebrafish model system will allow solutions to long-standing questions. For example, how is the centrosome regulated? Exactly what does it do in cell division? What is its relationship to basal bodies and ciliogenesis? It is the purpose of this review to summarize and outline the current state of knowledge about the centrosome and its relative, the basal body, in zebrafish.

Centrosomes in animal cells usually consist of $\gamma$-tubulin ring complexes $(\gamma$-TuRCs), centrioles, pericentriolar material and tubulins, along with a number of other centrosome-associated proteins. A previous proteomic analysis of isolated human centrosomes indicated about 
70 protein components and revealed the complexity of the centrosome [4]. The major components are briefly reviewed regarding our knowledge of most animal cells and then those of the zebrafish in particular. Centrosomes and the related basal bodies of cilia are important microtubule (MT)-organizing centers (MTOCs) of animal cells. A number of serious diseases have been linked to their dysfunction (reviewed in [5]). A major centrosomal-basal body protein, $\gamma$-tubulin, a member of the tubulin superfamily, appears to play a central role in MTOC activity; nevertheless, our specific knowledge about $\gamma$-tubulin's role is far from complete. Like other tubulins, such as $\alpha$ - and $\beta$-tubulin, $\gamma$-tubulin exists as both a soluble and a polymer pool, albeit at about $1 \%$ the abundance of $\alpha$ - and $\beta$-tubulins. Very enlightening work on Drosophila and Xenopus has revealed that the $\gamma$-TuRCs are composed of about $13 \gamma$-tubulin subunits, together with several different proteins called " $\gamma$-tubulin complex proteins" ( $\gamma$-tubulin ring-associated protein, or GRIP) [6-8], and are found at the minus ends of microtubules associated with centrosomes. The association of the $\gamma$-TuRCs with the centrosome appears to be dynamic, as seen in Caenorhabditis elegans early cleavage embryos expressing $\gamma$-tubulin-GFP [9]. Clearly, the centrosome duplication and other dynamic processes are synchronized with the cell cycle, presumably by the cyclin-dependent kinase (CDK) system, but the exact mechanism by which they occur is unclear. How $\gamma$-tubulin and its associated proteins are recruited to and docked at the centrosome is also largely unknown. The microtubule cytoskeleton is essential for a variety of cellular processes, including cell movement, organelle transport and cell division and, for primary cilia, sensation and signaling. Moreover, in oocytes and early embryos, microtubules have been implicated in localization of important embryonic determinants such as bicoid mRNA in Drosophila [10] and Vg1 mRNA in Xenopus [11], as well as trafficking cell components such as $\beta$-catenin to cytokinesis furrows in cleaving zebrafish embryos [12]. Recently, it was reported that nocodazole, a MT inhibitor, abolished translocation of the dorsal determinant Wnt8a in zebrafish embryos, emphasizing the importance of MT in zebrafish development [13]. MTOCs organize MTs by initiating noncovalent assembly of $\alpha \beta$-tubulin heterodimers, anchoring them at their minus ends and facilitating MT extension at the rapidly growing plus ends. These complicated dynamic properties involve the functions of numerous MT-associated proteins. MTOCs thus organize and control the MT network both spatially and temporally, including that of cilia. They also help to define the MT surface lattice [14]. The morphology, subcellular localization and molecular make-up of MTOCs vary across different species and different cell types within single species.
Although the main topic of this review is the centrosome, it is becoming increasingly clear that centrosomes and basal bodies are intimately related, especially in some cell types, such as stem cells containing primary cilia. Basal bodies are derived from centrosome components, especially the mother centriole, which is thought to direct assembly of the axoneme (reviewed in [15-17]). During the cell cycle, the axoneme is disassembled and the basal body components are used to reconstitute the centrosome [18]. Thus the centrosome and basal body are intimately related and composed of many of the same components, and their formation is regulated in concert with the cell cycle.

\section{General centrosome structure and function}

The centrosome and related basal body are thought to provide sensation, motion and cell division to the eukaryotic cell and thus are ancient structures believed to be found in the very first eukaryotes (reviewed in [19-21]). The centrosome and basal body structures are more than MTOCs [22] in that they may act as scaffolds for signal cascades and may contribute to disease states such as cancer [23] and ciliopathies [5]. In most animal cells, centrosomes are composed of a pair of centrioles surrounded by an amorphous cloud of electron-dense material, the pericentriolar material (PCM) [24]. Mass spectrometric analysis of purified human centrosomes has revealed 47 previously known centrosome components in four major protein groups: (1) structural components including tubulins, $\gamma$-tubulin complex components, centrins, A-kinase anchoring protein 450 (AKAP450), pericentrin, ninein, PCM-1 and centrioleassociated proteins; (2) regulatory molecules, including cyclin/CDK1, protein kinase A (PKA), Plk1, type 1 pyrophosphatase (PPase 1) and PPase 2A; (3) motor proteins, including dynein and dynactins; and (4) heat shock proteins, including Hsp90 and Hsp73 [4,25]. An additional 64 proteins were newly identified. Many of these were coiled-coil domain proteins. The PCM is largely proteinaceous [26,27] and consists of a matrixlike structure (also referred to as the "centrosome scaffold") [24,28,29]. One characterized PCM protein required for in vivo MT nucleation is $\gamma$-tubulin. In Drosophila and Xenopus, $\gamma$ tubulin contributes to macromolecular complexes or $\gamma$ TuRCs, with a characteristic ring structure (approximately $25 \mathrm{~nm}$ in diameter), together with a variety of associated proteins [6,29-31]. Hundreds of 32S $\gamma$-TuRC tether to the centrosome scaffold to serve as the site of origin for MTs $[24,28,29]$ and are required for spindle assembly and progression through mitosis [7,32-34]. Thus the centrosome is the primary site for MT nucleation, and the centrosomal $\gamma$-TuRC is thought to be necessary for anchoring of MT minus ends to centrosomes [35-39]. In addition to playing roles in 
centrosome-dependent MT nucleation [40], $\gamma$-tubulin has also been found to be closely associated with the PCM and centrioles and to be a core component of the centriole [41]. It plays a key role in daughter centriole formation [42] or in the nucleation and/or stabilization of the centriolar MTs [43].

\section{Pools of $\gamma$-tubulin}

In mammalian cells, a significant fraction of the total pool of $\gamma$-tubulin is found in cytosolic complexes [43]. Inside the cell, $\gamma$-tubulin is located at the centrosome as $\gamma$ TuRCs and is also distributed in the cytoplasm as a soluble pool of inactive smaller complexes that constitute an exchangeable stock of material [43-46]. Recruitment of $\gamma$-tubulin to sperm basal bodies is necessary for the assembly of a MT nucleation-competent paternal centrosome [7,47]. Using immunofluorescence and GFP reporter construct techniques, $\gamma$-tubulin was shown to be associated with centrosomes dynamically in mitotic cells, being massively recruited at prophase and released at anaphase-telophase. This accumulation in mitotic centrosomes is dramatic during the first embryonic divisions in C. elegans [48]. Moreover, fluorescence measurements suggest that the amount of antigenic $\gamma$ tubulin increases during mitosis and that, in HeLa cells, the total amount of $\gamma$-tubulin in the spindle is larger than the amount of $\gamma$-tubulin in the spindle poles [49]. The cell-stage distribution of $\gamma$-tubulin varies between animal cells of different species and between cells of different tissues within the same species. These observations imply that both the localization and the concentration of $\gamma$-tubulin are highly regulated during the cell cycle and that the regulation may vary between cell types and between species [49]. Thus understanding how $\gamma$-TuRCs are recruited to and docked at the centrosome is essential for understanding the regulation of MT nucleating activity. The function of the soluble cytoplasmic $\gamma$-tubulin remains unclear. Also, very little is known about how the $\gamma$-TuRC is assembled and tethered in the centrosome. Moreover, the redistribution of centrosomal proteins to specific sites of the cell is poorly understood, and the mechanisms controlling MT nucleation within the living cell are still unclear. Thus, though considerable progress has been made in the understanding of centrosomes, significant work remains to be done. The zebrafish system shows promise in providing more insight.

\section{$\boldsymbol{\gamma}$-Tubulin ring complex components in zebrafish}

In 1989, a new member of the tubulin family, $\gamma$-tubulin, was discovered in Aspergillus nidulans [32] and was found to be a major conserved component of the centrosome [33]. The discovery led to a major research effort over the next few years aimed at elucidating the structure and function of $\gamma$-tubulin. The primary protein sequence of $\gamma$-tubulin has been compared to $\alpha$ - and $\beta$ tubulins $[50,51]$, as well as to other tubulin family members, including $\delta$ - and $\varepsilon$-tubulins [52]. These results indicated a high degree of sequence homology when comparisons among divergent species were made. For example, $\alpha$-tubulins, $\beta$-tubulins and $\gamma$-tubulins were, respectively, $89 \%$ to $95 \%, 88 \%$ to $94 \%$ and $72 \%$ to $94 \%$ homologous. The $\delta$ - and $\varepsilon$-tubulin family members were the most varied, having $47 \%$ to $57 \%$ and $58 \%$ homology, respectively. Such high degrees of homology may allow the use of antibodies developed for one species in another species. This is the case for $\gamma$-tubulin in zebrafish. The mouse monoclonal antibodies GTU-88 and TU-30 were demonstrated to cross-react with zebrafish $\gamma$-tubulin on Western blots (Figure 1) [53]. Both antibodies label centrosome spindle poles in zebrafish early embryos as well (Figure 2). For example, GTU-88 recognizes the fully conserved epitope 38 EEFATEGTDRKDVFFY 53 in the $\mathrm{N}$ terminus of human and zebrafish $\gamma$-tubulin. TU-30 recognizes the epitope 434 EYSAATRPDYISWGTQ 449 at the zebrafish $\gamma$-tubulin $\mathrm{C}$ terminus. Human $\gamma$-tubulin (the antigen sequence used) has one amino acid difference in the TU-30 epitope, with $\mathrm{H}$ at residue 436 instead of $\mathrm{S}$ in zebrafish. Armed with these antibodies, investigators, including those working on zebrafish centrosome questions could make progress in understanding how centrosomes function. For example, large accumulations of $\gamma$-tubulin have been found to be associated with spindle poles of early cleavage stages [54].

Although it was previously known that $\alpha \beta$-tubulin dimers assemble in vitro under certain conditions, it was also clear that, for animal cells, centrosomes are required for in vivo MT assembly [28]. Then investigators found evidence of large complexes containing $\gamma$ tubulin associated with the minus ends of MTs at the centrosome [7]. However, $\gamma$-tubulin was also found to be associated with the mitotic spindle [49] and the midbody at cytokinesis [55]. Groups led by Bruce Alberts simultaneously reported in the journal Nature the structure of Xenopus $\gamma$-tubulin ring complexes associated with the centrosome and hypothesized that these acted as templates for nucleating new MTs $[8,29]$. The complexes (later termed " $\gamma$-TuRCs") were found to contain at least seven distinct proteins and to have an open ring structure with a diameter of $25 \mathrm{~nm}$ [31]. Centrosomes can be disassembled by high salt to reveal a filamentous "centromatrix" onto which $\gamma$ TuRCs can be reassembled in vitro [56]. In addition, Drosophila embryos have two distinct $\gamma$-TuRCs, large $2.2 \mathrm{MDa}$ and small $280 \mathrm{kDa}(\gamma$-TuSC) versions with differing MT nucleating capabilities $[6,57,58]$. The smaller version is thought to be the essential core 


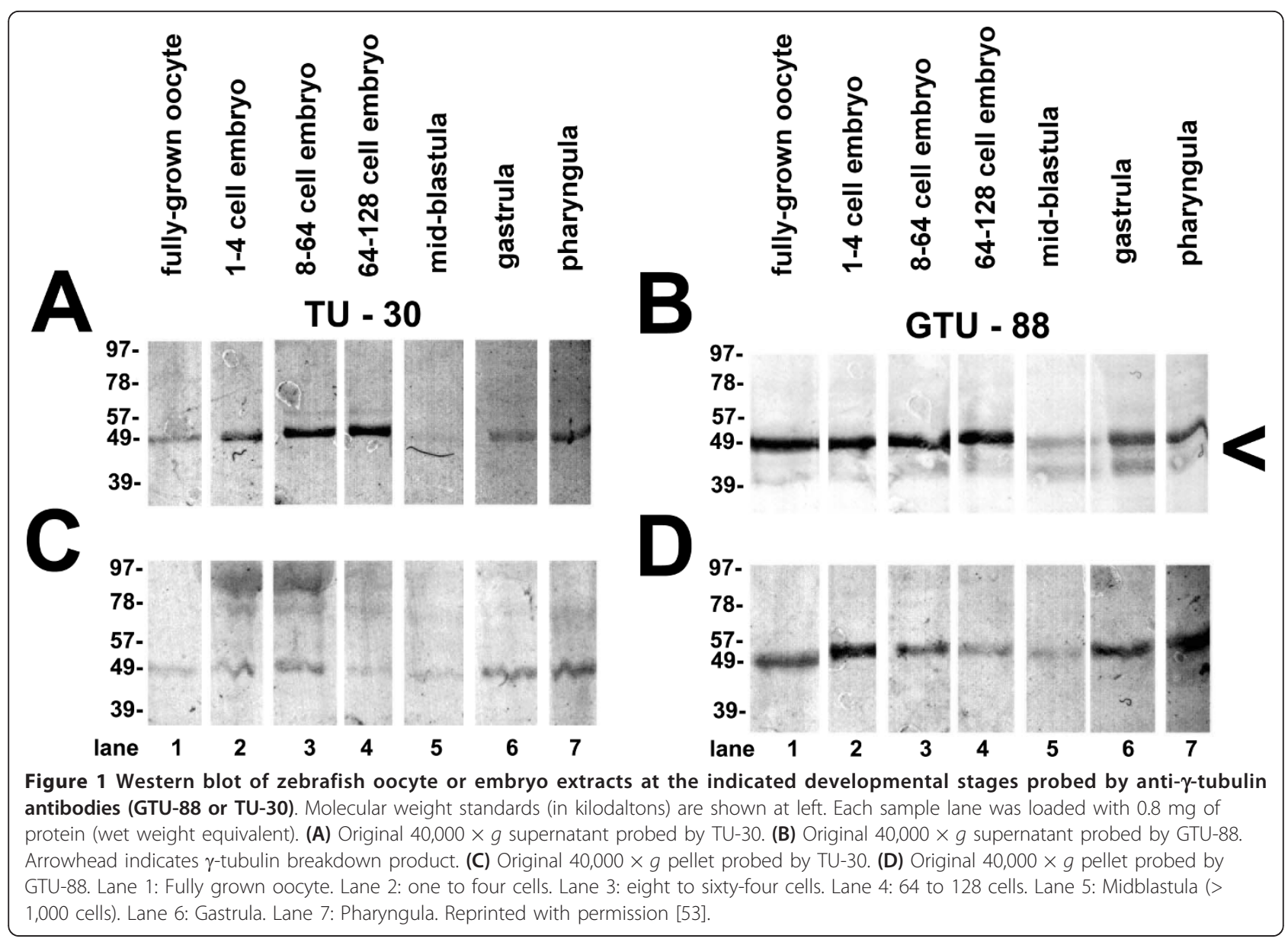

consisting of two $\gamma$-tubulin subunits and one copy each of spindle pole body components (Spc), Spc97 and Spc98 [59], with the latter being yeast homologs [60] of $\gamma$-tubulin complex proteins 2 and 3, respectively [61]. The $\gamma$-TuSCs form filaments with 13-part symmetry similar to a MT and have been modeled to nucleate MTs in various systems (Figure 3) [59,60].

Zebrafish oocytes and embryos have large complexes containing $\gamma$-tubulin that range in size to over $2 \mathrm{MDa}$ by column chromatography [53]. These results are similar to those found in Xenopus and Drosophila [31] and suggest that a large pool of $\gamma$-TuRCs is stockpiled in the oocyte for use in the embryo, especially during the very rapid divisions of cleavage. Once cleavage begins in the zebrafish embryo, cell division occurs astonishingly fast, every 15 to 20 minutes [62,63]; thus, within 3 hours postfertilization, the embryo has over 1,000 cells, each of which has a centrosome! After reaching the midblastula transition, cell divisions slow somewhat, the maternal reserves of protein and mRNA decrease and the zygotic genome is first significantly expressed [63]. This applies also to $\gamma$-tubulin protein (Figure 1) and mRNA (Figure 4) in zebrafish embryos as both decrease during midblastula to early gastrulation and return to higher levels subsequently [53,64].

A National Center for Biotechnology Information database search revealed $\gamma$-tubulin complex proteins 2 to 5, HAUS augmin-like protein 6 and mitotic spindleorganizing proteins 1 and 2 in the zebrafish (Table 1 ). Generally, the $\gamma$-tubulin complex protein 2 through 5 sequence homology was high compared with other vertebrates. This finding is in agreement with a report of a cross-reaction of zebrafish proteins with Xenopus Xgrip 109 (analogous to Spc98 and $\gamma$-complex protein 3 (GCP3)) and Xgrip 195 polyclonal antibodies [53]. A putative zebrafish ortholog for a newly discovered human $\gamma$-TuRC component, GCP8, has recently been reported [65]. GCP8 is a small protein (about $20 \mathrm{KDa}$ ) that may be part of the core $\gamma$-TuSC.

\section{General centriole structure and function}

Centrioles are cylindrical structures with ninefold radial symmetry and triplets of short MTs forming the outside wall in many species. A pair of centrioles oriented to each other at about a right angle is found in centrosomes and basal bodies [66]. Although centrioles are 


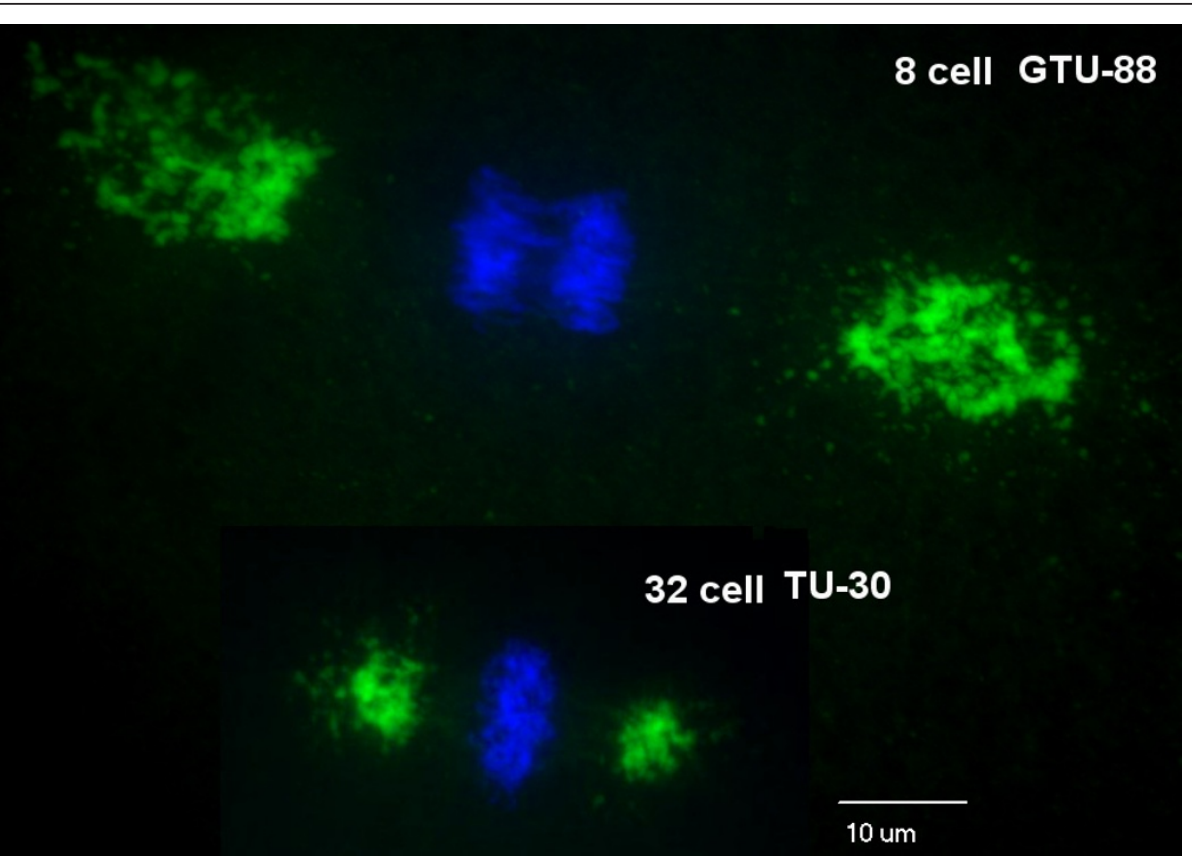

Figure 2 Centrosomes at the spindle poles of the blastomere of an eight- or thirty-two-cell paraformalin-fixed zebrafish embryo depicted by $\gamma$-tubulin antibody GTU-88 or TU-30, respectively, and Alexa Fluor 488 dye-conjugated second antibody (green) as well as chromosomes stained with 4',6-diamidino-2-phenylindole (blue). Z-axis projections of approximately 60 optical sections photographed with an Olympus spinning disk confocal microscope using a $60 \times$ oil immersion lens objective. Note the size differences, with the $\gamma$-tubulin array being smaller in centrosomes of 32-cell compared to 8-cell embryos.

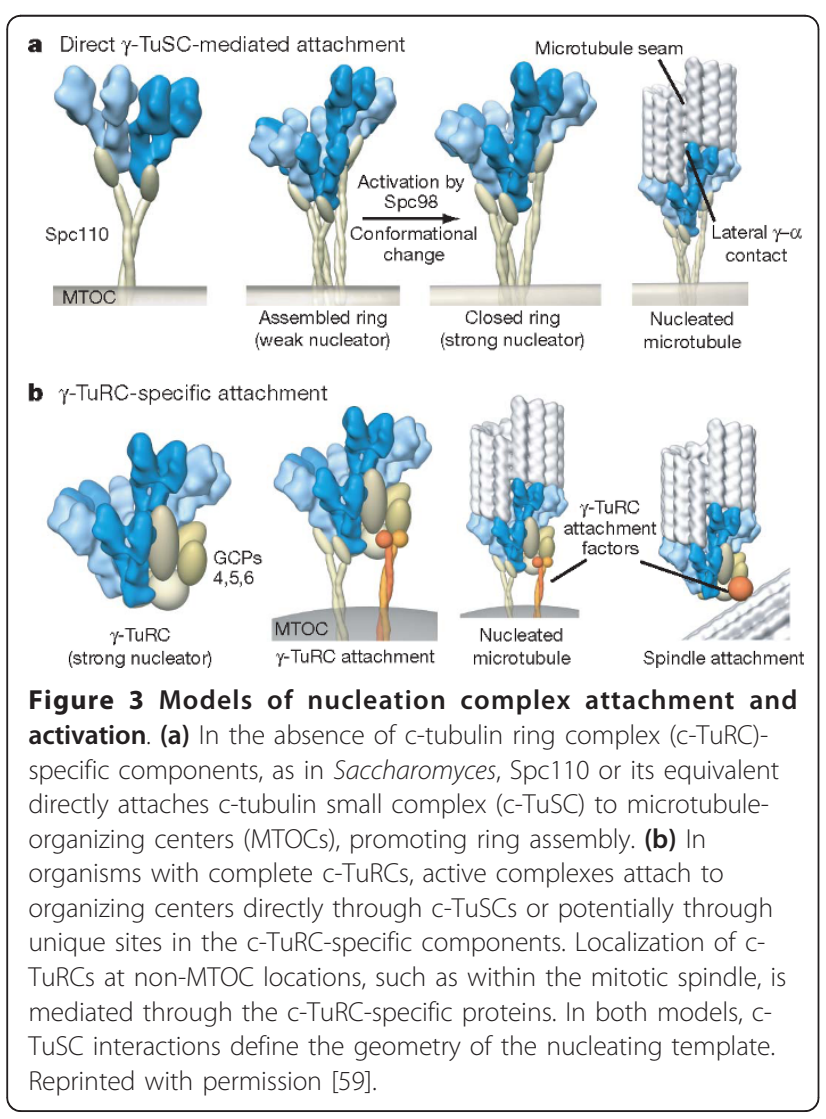

found in most animal cells, they are notably absent in oocytes and eggs until the latter are fertilized. The sperm provides the initial centriole to reconstitute centrosomes in the zygote [67]. In preparation for cell division, a procentriole, or daughter, forms at the base of each mother centriole by first forming a cartwheel structure, then forming MTs [66]. The cartwheel has a ninefold symmetry composed of spindle assembly abnormal SAS-6 homodimers with coiled-coil domains radiating outermost as spokes [68]. This process of centriole replication or procentriole formation occurs in two ways: (1) the canonical pathway, involving motherdaughter proximity and resulting in exactly one net new centriole pair and (2) the de novo pathway, particularly active in ciliogenesis in ciliated vertebrate epithelial cells, involving multiple procentriole formations from fibrous granules and deuterostomes not necessarily containing existing centrioles [66]. The mother centriole is older and has specializations that include filaments or appendages [66] and additional proteins such as centriolin [69]. In addition, the mother centriole produces the cilium from the basal body [66]. Questions remain about the underlying factors that produce differences between the mother and daughter centrioles' ability to organize centrosomes or basal bodies and, in turn, to organize a spindle or a cilium, respectively. Other areas of centriole and/or basal body biology that need further 


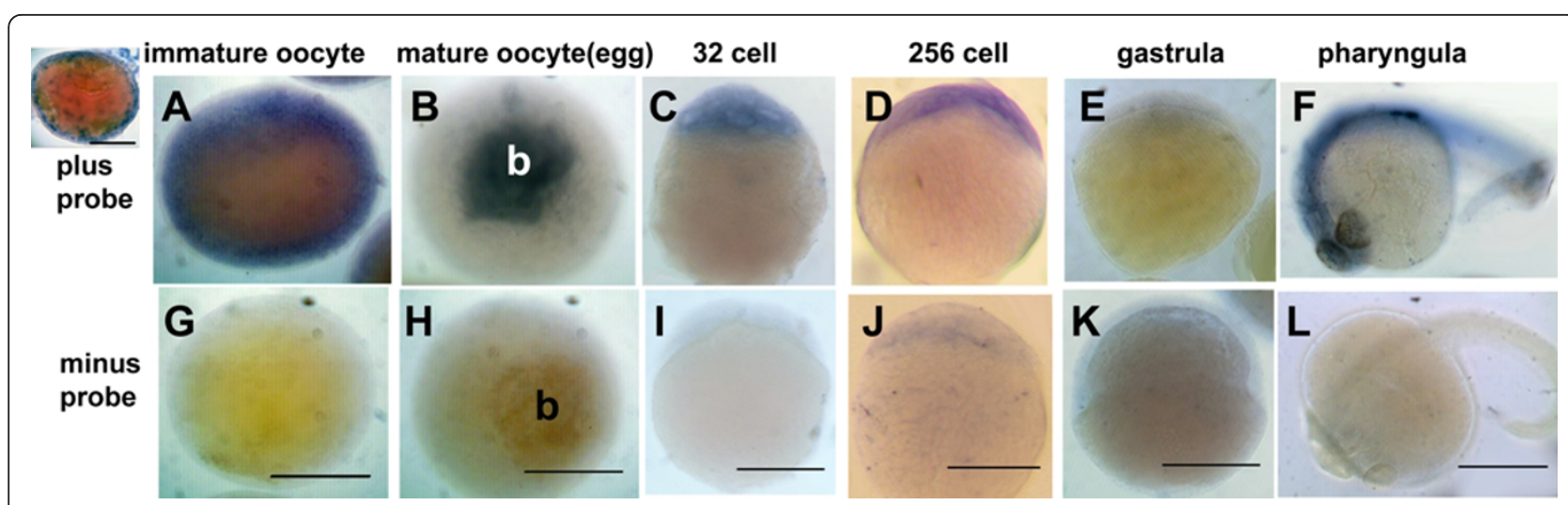

Figure 4 In situ hybridization (probed with fluoroscein isothiocyanate-oligo- $\gamma$-tubulin probe) of different stages of zebrafish oocytes and embryos. (A) and (G) Fully grown, immature oocytes. (B) and (H) Mature oocytes or eggs) and embryos. (C) and (I) 32-cell embryos. (D) and (J) 256-cell embryos. (E) and (K) Approximately 30\% epiboly gastrula. (F) and (L) pharyngula). The top panels in (A) through (F) show the "with probe" treatments, and the lower panels in $(G)$ through $(L)$ show the corresponding "without probe" treatments. The primordial blastodisc (b) that forms at the animal pole of the egg during oocyte meiotic maturation labeled intensely with the probe (B) Inset: Immature oocyte probed after hemisection showing cortical label. Anti-FITC secondary antibody conjugated to alkaline phosphatase and the substrate 3,3'diaminobenzidine were used to develop color. The specimens were dehydrated in $100 \% \mathrm{MeOH}$ and placed in clearing media containing benzyl benzoate and benzyl alcohol (2:1 dilution) prior to being mounted on slides. Scale bar $=250 \mu \mathrm{m}$. Reprinted with permission [64].

investigation include (1) temporal and genetic factors involved in aging and positioning of centrioles relative to the formation of centrosomes versus basal bodies, (2) the role of centriole condition in stem cell maintenance or differentiation and (3) centriole fate and mechanism of loss in oocytes and other cells that lose centrioles normally (reviewed in [70]).

\section{The centriole in zebrafish}

A female sterile maternal effect mutation in the cellular atoll (cea) gene in zebrafish produces aberrant mitosis beginning with the second cleavage $[71,72]$. Maternally mutant cea embryos produce normal mitotic spindles for the first cleavage only and thereafter fail to produce normal spindles (Figure 5). Interestingly, paternal cea mutants mated with wild-type females produce defects in the first cleavage spindle, but normal ones subsequently. Cea encodes SAS-6, a coiled-coil protein associated with the centrioles and
SAS-6 splice variants fused to mCherry, colocalize with $\gamma$-tubulin at the centrosomes (Figure 6). Very recently, it was reported that, in cultured cells, SAS- 6 is targeted by an E3-ubiquitin ligase that uses an F-box protein, FBXW5, as a targeting subunit [73]. FBXW5 is in turn regulated by Polo-like kinase 4 (PLK4), thus degradation of SAS- 6 by this mechanism limits centrosome reduplication. It will be interesting to see if FBXW5 acts in a similar way in zebrafish. SAS-6 has been shown to have a nine-part "cartwheel" oligomeric structure, suggesting a template function for centriole assembly in C. elegans [68] and, importantly, for zebrafish as well [74]. The homodimers of SAS-6 with ninefold symmetry were shown to fit most closely with actual procentriole cartwheels compared with those with other symmetries (Figure 7) [74]. Work in Drosophila has also implicated PLK4 in centriole assembly, but in this system it pairs with SAS-4 and asterless (Asl) (CEP152 in humans) [75].

Table 1 Results of an NCBI database search for $\gamma$-tubulin complex component proteins in zebrafish ${ }^{a}$

\begin{tabular}{lcccc}
\hline Protein & Amino acids & Cal. MW (Da) & Identity (\%) & Gap (\%) \\
\hline$\gamma$-tubulin complex protein 2 & 882 & 101,642 & 79 to 88 & 0 \\
$\gamma$-tubulin complex protein 3 & 899 & 102,403 & 77 to 79 & 3 \\
$\gamma$-tubulin complex protein 4 & 668 & 76,008 & 88 to 89 & 72 to 73 \\
$\gamma$-tubulin complex protein 5 & 1015 & 117,437 & 30 to 48 & 1 to 2 \\
HAUS augmin-like protein 6 & 794 & 89,594 & 80 to 90 & 5 to 8 \\
Mitotic spindle-organizing protein 1 & 75 & 8,051 & 52 to 61 & 5 to 8 \\
Mitotic spindle-organizing protein 2 & 153 & 16,177 & & 0 \\
\hline
\end{tabular}

${ }^{a} \mathrm{NCBI}$, National Center for Biotechnology Information. The molecular weight (MW) was calculated (Cal.) on the basis of the primary sequence using the program available at http://www.encorbio.com/protocols/Prot-MW.htm (EnCor Biotechnology Inc, Gainesville, FL, USA). The identity and gap percentages are based on blastp of zebrafish protein sequences with other vertebrates, including human and mouse. 


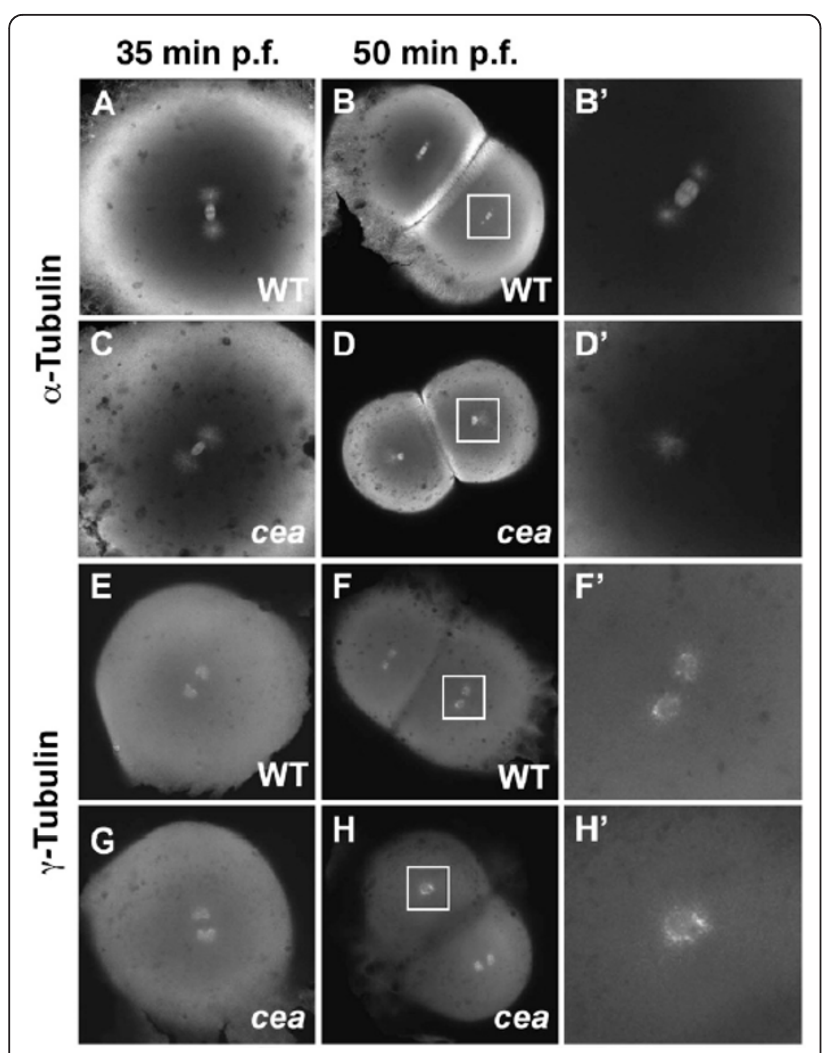

Figure 5 Spindle organization and centrosome duplication defects in maternally mutant cellular atoll (cea) zebrafish embryos. (A) to ( $\left.\mathbf{D}^{\prime}\right)$ Embryos labeled with anti- $\alpha$-tubulin antibody. (A) and (B') Fixed wild-type embryos. (C) and (D') Mutant embryos. Spindle organization is normal in the mutant embryos immediately prior to the first cell division (35 minutes postfertilization (pf) (C); compare with (A)) but is defective in a fraction of blastomeres in the next cleavage cycle (50 minutes pf $(D)$ and $\left(D^{\prime}\right)$; compare with $(B)$ and $\left.\left(B^{\prime}\right)\right)$. (E) to $\left(H^{\prime}\right)$ Embryos labeled with anti- $\gamma$-tubulin antibody. $(\mathrm{E})$ and $\left(\mathrm{F}^{\prime}\right)$ Fixed wild-type. $(\mathrm{G})$ and $\left(\mathrm{H}^{\prime}\right)$ Mutant. Centrosome duplication appears normal immediately prior to the first cleavage division (35 minutes pf (G); compare with (E)) but is defective in a fraction of the blastomeres in the following cleavage cycle (50 minutes pf $(H)$ and $\left(H^{\prime}\right)$; compare with $(F)$ and $\left(F^{\prime}\right)$ ). Animal views: $\left(B^{\prime}\right),\left(D^{\prime}\right),\left(F^{\prime}\right)$ and $\left(H^{\prime}\right)$ are enlargements of the area indicated by the squares in (B), $(D),(F)$ and $(H)$, respectively. Reprinted with permission [71].

The maternal effect gene futile cycle (fue) is necessary for pronuclear congression and for normal mitotic spindle formation [54] in cleaving zebrafish embryos. It is particularly notable that fue mutant embryos seem to produce normal centrosomes (Figure 8) even when DNA replication and mitotic spindle assembly are deranged. This may be due to a reduced level of cellcycle checkpoint surveillance in cleaving embryos [76]. Cytokinesis furrow formation is impaired in the mutant phenotype of another zebrafish maternal effect gene called cellular island (cei), but mitotic spindle formation appears normal [77]. Cleaving embryos produce a transient furrow MT array (FMA) that consists of MTs oriented perpendicular to the cleavage furrow [77]. The FMA is thought to help traffic cytoskeletal components such as $\beta$-catenin to the furrow [12]. Thus the cei mutant phenotype indicates that the FMA and spindle MTOCs must be separate because spindles are normal, but FMAs are not. The idea of multiple MTOCs in a given cell is not novel, as there are many examples described in the literature, such as ciliated epithelial cells that may have many basal bodies (reviewed in [78]).

\section{Centrins}

Centrins are small $\mathrm{Ca}^{2+}$-binding proteins of the EF-hand superfamily related to calmodulin, troponin $\mathrm{C}$ and parvalbumin [79] that are associated with centrioles, but also may be found elsewhere, such as in the nucleus. In human cells, more than $90 \%$ of the centrin is not centrosome-associated [80]. In mammalian cells, centrin 2 is required for centriole duplication [81], and use of GFP-centrin constructs have shown differential behavior of mother and daughter centrioles [82,83]. Some centrins are usually associated with centrosomes, except in preimplantation porcine embryos [84], and are also found in basal bodies, including the connecting cilium of photoreceptors [79]. Centrin 2 has been shown to self-assemble into fibers in the presence of $\mathrm{Ca}^{2+}$ reminiscent of those associated with basal bodies [85]. In addition, a Chlamydomonas centrin mutant has acentriolar spindle poles and lacks rhizoplasts that normally join the centrioles to the nucleus and result in increased chromosome loss and genomic instability [86]. Phosphorylation of human centrin at serine 170 during the $\mathrm{G}_{2} / \mathrm{M}$ phase has been implicated as the signal for centriole separation before centrosome duplication [87]. Another prominent signaling role for centrin is its interaction with transducin within the connecting cilium of photoreceptor cells [88].

\section{Centrin in zebrafish}

In zebrafish, centrin constructs containing reporters have been used to indicate centrosome position in migrating neurons in vivo [89], polarization of retinal ganglion cells [90] and interkinetic nuclear migration in retinal cells [91]. A transgenic mouse line expressing GFP-centrin 2 driven by a constitutive promoter was found to display a single pair of fluorescent centrioles in most cells examined; however, it was noted that some cells of the adult brain seemed to accumulate aggregations of fusion protein [92]. Overexpression of GFP-centrin was found to produce large aggregates that caused disarray of the wild-type centrin in Chlamydomonas [93]. Thus caution should be exercised when utilizing centrin reporter constructs. A comparison of zebrafish, 


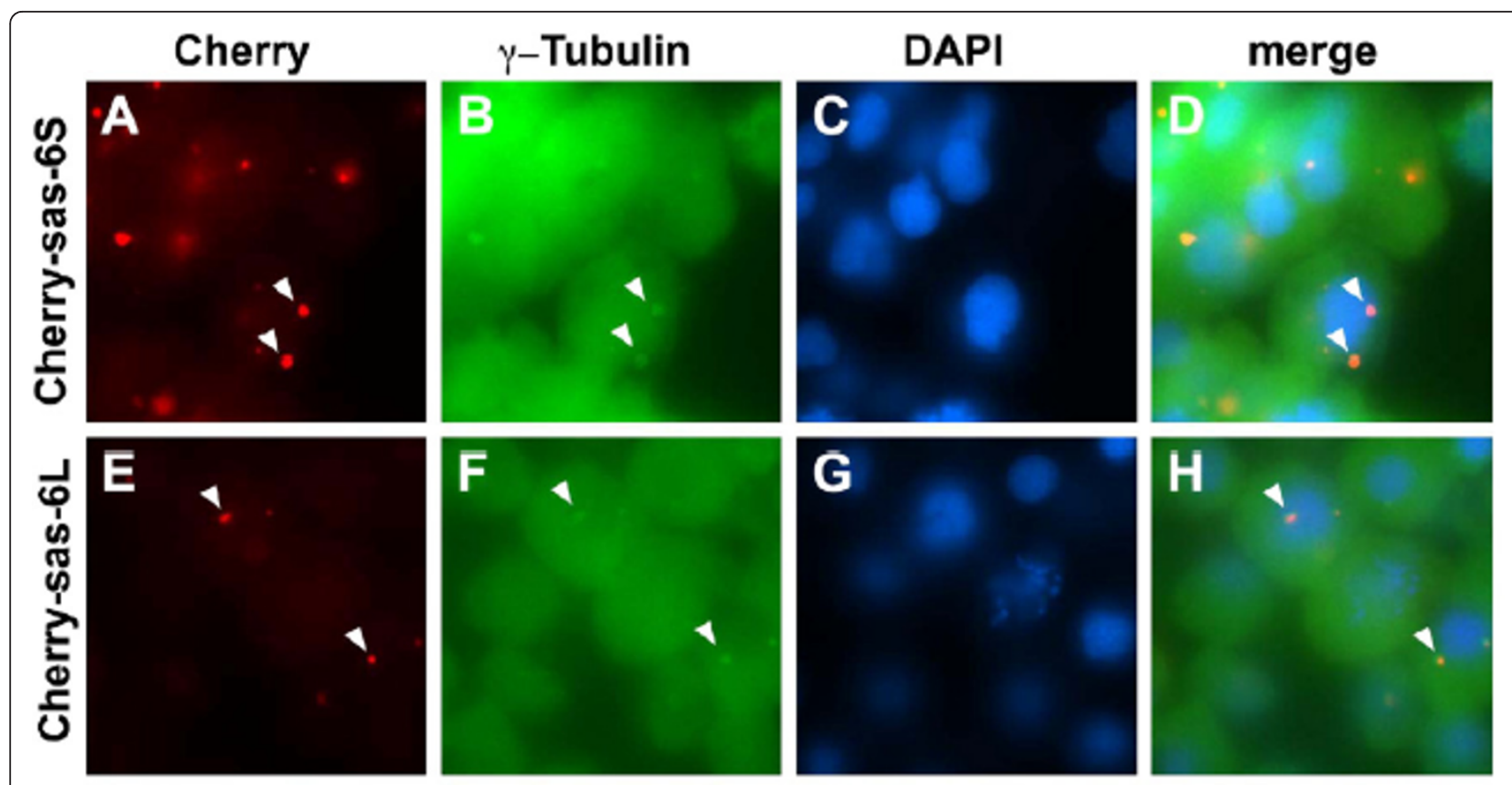

Figure 6 Cea/Sas-6 localizes to zebrafish centrosomes. Expressed fusions of mCherry and Sas-6 splice forms colocalize in cytoplasmic structures containing $\gamma$-tubulin (arrowheads), markers for centrosomes. Fields of cells in embryos are fixed at 50\% epiboly. Reprinted with permission [71].

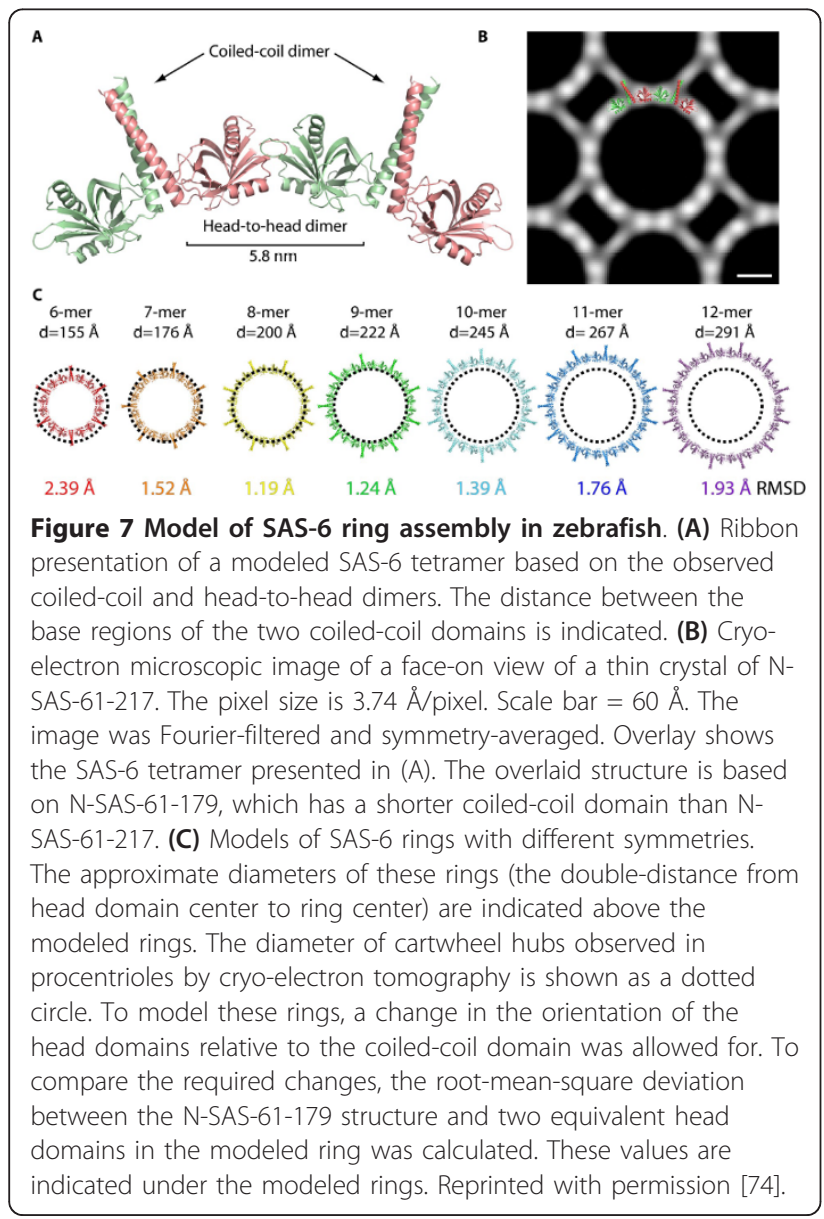

mouse and Xenopus centrin 2 protein sequences reveals a very high degree of homology, suggesting that reagents, such as antibodies, developed for mammals may also be useful in zebrafish (Table 2).

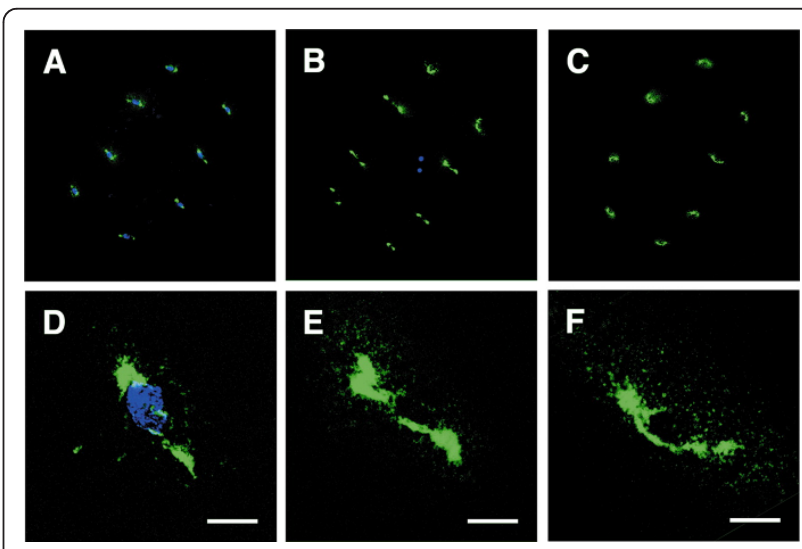

Figure 8 Centrosome duplication is not affected in futile cycle (fue) mutants. Centrosomes at the eight-cell stage during interphase visualized with an antibody directed against $\gamma$-tubulin (green) and nuclei labeled with 4',6-diamidino-2-phenylindole (blue) from (A) a wild-type embryo, (B) a fue embryo and (C) an embryo treated with the DNA replication inhibitor aphidicolin. (D) through (F) Enlargements of single-centrosome pairs shown in (A) through (C), respectively. Centrosomes are present and able to duplicate in all fue cells as well as the (anucleate) cells of aphidicolin-treated embryos, demonstrating that the centrosomes can duplicate independently of nuclei. Scale bars $=20 \mathrm{~mm}$. Reprinted with permission [54]. 
Table 2 Centrin 2 amino acid sequence comparison among zebrafish, Xenopus and mouse ${ }^{a}$

1 MASNYKKPSLGVTTQRKKPVPKPELTEEQKQEIREAFDLFDTDGAGTIDVKELKVAMRAL 60 XENTR
1 MASNFKKTTMASSAQRKRMSPKPELTEDQKQEIREAFDLFDADGTGTIDIKELKVAMRAL 60 MOUSE
1 MASGFRK-SSASANQRKKAGPKPELTEEQKQEIKEAFDLFDTDGSGTIDVKELKVAMRAL 59 DANRE
61 GFEPKKEEIKKMIADIDKEGTGKISFGDFMSAMTQKMAEKDSKEEIMKAFRLFDDDETGK 120 XENTR
61 GFEPKKEEIKKMISEIDKEGTGKMNFSDFLTVMTQKMSEKDTKEEILKAFKLFDDDETGK 120 MOUSE
60 GFEPKKEEIKKMIADIDKEGSGVIGFSDFLSMMTQKMSEKDSKEEILKAFRLFDDDCTGK 119 DANRE
121 ISFKNLKRVAKELGENLTDEELQEMIDEADRDGDGEVNEQEFLRIMKKTSLY-172 XENTR
121 ISFKNLKRVAKELGENLTDEELQEMIDEADRDGDGEVNEQEFLRIMKKTSLY-172 MOUSE
120 ISFKNLKRVAKELGENLTDEELQEMIDEADRDGDGEINEQEFLRIMKKTNLYG 172 DANRE

${ }^{a}$ Xenopus centrin 2 (Q28HC5_XENTR), mouse centrin 2 (CETN2_MOUSE) and zebrafish centrin 2 (B1P0R9_DANRE). Numbers refer to primary structure.

\section{Pericentrin}

Antibodies from human scleroderma patients have been used to discover another centrosomal protein, called "pericentrin," with a molecular weight of about $220 \mathrm{kDa}$ [36]. Pericentrin was found to associate with $\gamma$-TuRCs and form a lattice that enlarges, then disassembles with the cell cycle [35]. Kendrin, a larger splice variant (about $380 \mathrm{kDa}$ ) of the PCNT pericentrin gene, was discovered in human cells and was found to bind calmodulin $[94,95]$. In kendrin, also called "pericentrin B," overexpression was found in carcinoma cells known to have centrosomes of abnormal size and number [94]. Some uncertainty exists regarding the number and size of pericentrin isoforms and splice variants [96]. Nevertheless, pericentrin derangement has been implicated in a number of disease states, including Seckel syndrome, microcephalic osteodysplastic primordial dwarfism, cancer, ciliopathies and mental disorders such as schizophrenia [97]. It has been suggested that this diversity of diseases is attributable to the many binding partners of pericentrin, including $\gamma$-tubulin, $\gamma$-TuRCs, PCM1, AKAP450, DISC-1, Chk1, kinases, intraflagellar transport (IFT) and PC2 [97]. Pericentrin and AKAP450 bind to a $\gamma$-tubulin complex binding protein called CDK5RAP2 via a CM-2-like motif that is also conserved in zebrafish [98].

\section{Basal bodies in zebrafish and relation to cilia}

Ciliogenesis and the cell cycle are interrelated, as are the basal body and centrosome (Figure 9). This relationship has garnered considerable scientific interest recently [16,17,99-102]. On the basis of this work, cilia, especially primary cilia, have assumed a new elevated status since the discovery of important functions provided by these organelles. These functions include (1) extracellular signaling for Sonic hedgehog, wnt and platelet-derived growth factor pathways; (2) sensing fluid flow in kidney tubules and cerebrospinal ventricles; and (3) determination of bilateral left-right patterning. These functions are in addition to the well-known cellular functions related to cilia, including cell motility, directed fluid flow and sensory transduction, including vision, hearing and equilibrium. Recent work indicates the importance of primary cilia to disease states such as cancer, and "ciliopathies" such as retinal degeneration, polydactyly, situs inversus, mental retardation, encephalocele and cysts in the kidney, liver and pancreas [17]. Organizing the primary cilium is the $\gamma$-tubulin-containing basal body that is derived from the mother centriole of the centrosome [99]. The basal body and the primary cilium are assembled and disassembled in tune with the cell cycle by an unknown mechanism [17]. A particularly important finding is the discovery that critical signaling

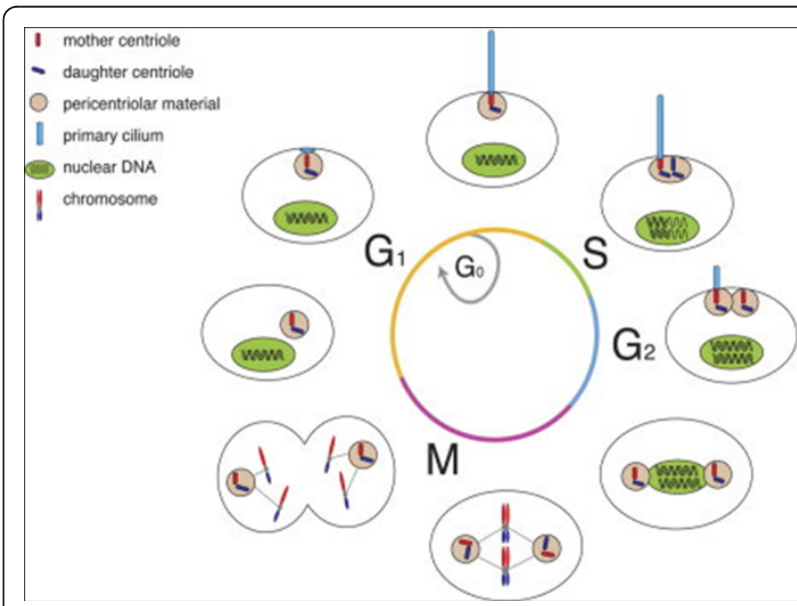

Figure 9 Dual use of the centrioles during cell cycle and primary cilium formation. In most cells, primary cilium formation first occurs during the $G_{1}$ phase following centrosomal docking to the membrane. Intraflagellar transport (IFT) and accessory proteins build the ciliary axoneme, which extends directly from the mother centriole's triplet microtubules. During this stage of the cell cycle, as well as during the Go phase, the cilium functions as a cellular antenna, interpreting extracellular signals such as Hedgehog and platelet-derived growth factor (PDGF). Upon entry into the $S$ phase, the cell's centrioles and the DNA begin to replicate. The centrioles reach maturity during the late $G_{2}$ phase, at which point the cilium is disassembled so that the engaged centrioles can be liberated for mitotic spindle formation. Once cell division is complete, the centrioles can proceed to ciliary reassembly in $G_{1}$. Reprinted with permission [18]. 
pathways are concentrated in the primary cilium, including Sonic hedgehog-Patched and Wnt-Frizzled ligand receptor systems [17]. Primary cilia are easily overlooked because many are rather short, about $5 \mu \mathrm{m}$ or less in length, and immotile, and only one per cell is usually present [103]. Markers that may be used for primary cilia include acetylated $\alpha$-tubulin (axoneme), $\gamma$-tubulin (basal body) and the Patched and Frizzled receptors (cilium membrane). The cilium is produced from the basal body, which in turn is derived from the centrosome $[15,104]$. Other factors that promote extension and maintenance of the cilium include the IFT components including IFT-A, IFT-B, dynein 2 and kinesin 2 .
Zebrafish primary cilia have been described or alluded to in an expanding number of recent reports [105-126]. A particularly informative study using the maternalzygotic oval (MZovl; ift88) zebrafish mutant that lacks all cilia revealed dampened Hedgehog signaling but normal Wnt signaling [108]. The MZovl mutants had normal basal bodies but failed to localize Smoothened to the cell membrane in association with basal bodies. In addition, left-right patterning was deranged, and the mutants also developed pronephric cysts and pericardial edema indicative of ciliopathies. Thus, though basal bodies are required, they do not appear to be sufficient for ciliogenesis or cilia maintenance. Other gene

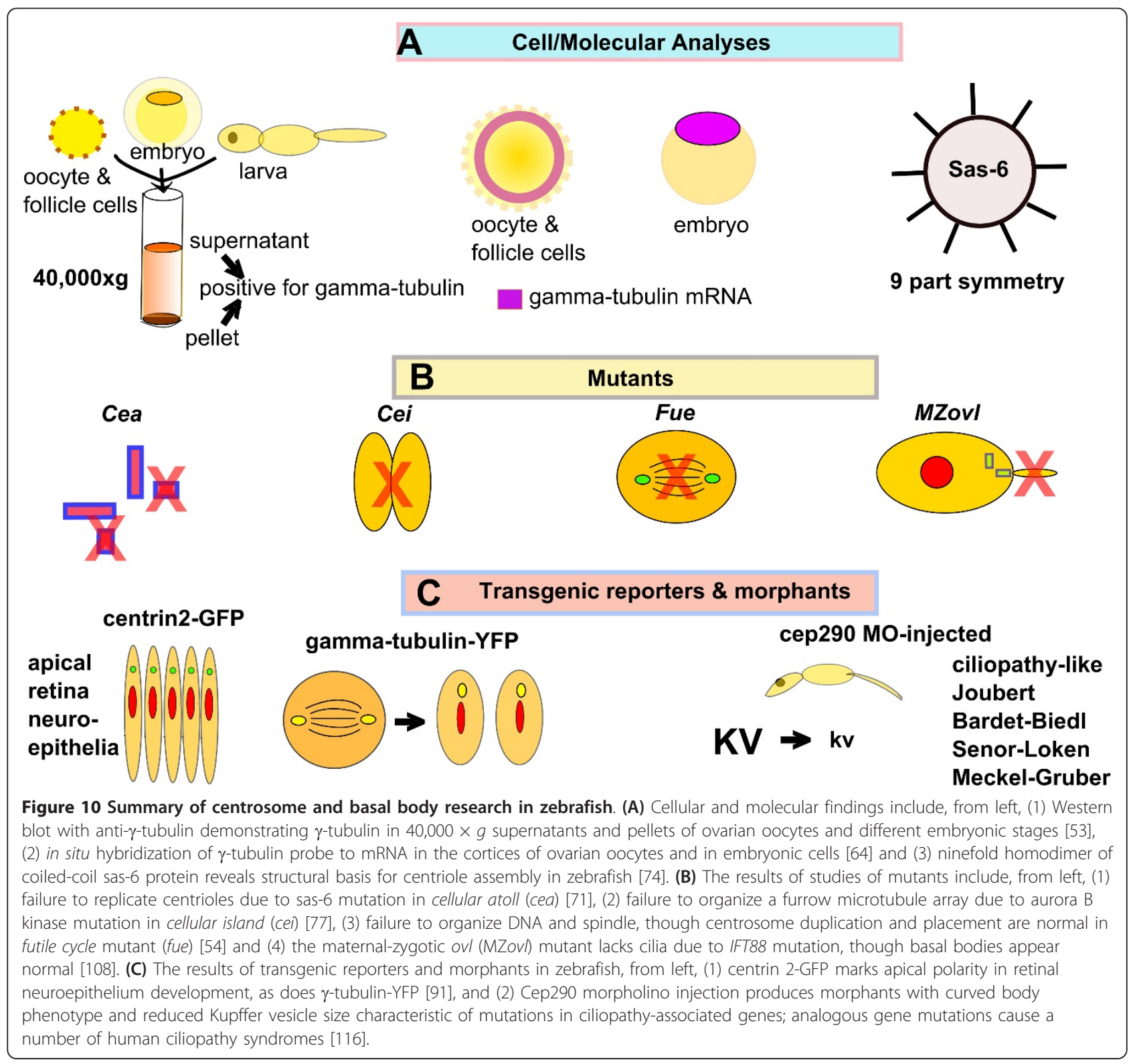


products reported to be involved in ciliogenesis in zebrafish include the zinc-finger protein iguana [118], geminin [119], fused [123], fibroblast growth factors FGF8 and FGF24 [115], Smoothened [106], the fleer gene product [112], cdc14B phosphatase [109], Cep70 and Cep131 [122], Rab11, Rabin8 and transport protein particle II (TRAPPII) [121] and Nde-1 [110].

\section{Zebrafish photoreceptors and basal bodies}

Gene knockdown of the centrosomal protein Cep290 resulted in zebrafish with visual defects and other symptoms of ciliopathies similar to those seen in Leber's congenital amaurosis, Meckel-Gruber syndrome, Joubert syndrome, Senor-Loken syndrome and Bardet-Bledl syndrome [116]. In addition, the visual defect may be rescued by expressing the $\mathrm{N}$-terminal region of the human Cep290 protein in the zebrafish. Cep290 is one of eleven ciliopathy genes that include $\operatorname{cc} 2 \mathrm{~d} 2 \mathrm{a}$ and involve retinal dystrophy as well as other defects, such as polycystic kidney [117]. The cc2 $\mathrm{d} 2 \mathrm{a}$ protein localizes to the photoreceptor-connecting cilium transition zone, and mutations result in visual defects as determined on the basis of electroretinograms in zebrafish [117].

\section{Conclusions}

The zebrafish model system shows promise in providing answers to long-standing questions involving the functions of centrosomes and the related basal bodies. This seems true in view of the genetic tractability of the zebrafish, that is, the many mutant and transgenic lines available, its favorable optical properties, ready accessibility to all stages of the life cycle and the possibility of high-throughput screening for therapeutic agents [127]. The major findings of centrosome and/or basal body research in zebrafish are summarized in Figure 10. Both $\gamma$-tubulin and $\gamma$-TuRC components, as well as SAS-6, the "cartwheel" centriole template, have been found in zebrafish. Zebrafish mutants such as cea, cei and fue have shown promise in providing insights into centrosome function. Centrin transgenic reporters in zebrafish have been useful in tracking centrosome position in vivo. Furthermore, zebrafish mutants such as MZovl, which lack cilia, may prove critical to understanding basal body-cilia dynamics and photoreceptor biology. Thus the zebrafish is proving to be a useful model with which to complement other vertebrate systems, such as the mouse, allowing experiments on and manipulations of developing embryos that are difficult or not feasible in mammals.

\section{Abbreviations}

AKAP: A-kinase anchoring protein; Asl: Asterless; cdc: cell division control; CDK5RAP2: cyclin-dependent kinase 5 regulatory subunit-associated protein 2; cea: cellular atoll; cei: cellular island; Cep: centrosomal protein; ChK-1: checkpoint 1 kinase; CM2: centrosomin 2; DAPI: 4',6-diamidino-2phenylindole; DISC-1: disrupted in schizophrenia 1; FGF: fibroblast growth factor; FITC: fluoroscein isothiocyanate; FMA: furrow microtubule array; fue: futile cycle; GCP: $\gamma$-complex protein; GFP: green fluorescent protein; GRIP: $\gamma$ tubulin ring-associated protein; $\gamma$-TuRC: $\gamma$-tubulin ring complex; $\gamma$-TuSC: $\gamma^{-}$ tubulin small complex; Hsp: heat shock protein; hpf: hours postfertilization; IFT: intraflagellar transport; kDa: kilodalton; MDa: megadalton; MT: microtubule; MTOC: microtubule-organizing center; MZovl: maternal-zygotic oval; Nde: nuclear distribution protein; PC2: polycystin; PCM: pericentriolar material; PDGF: platelet-derived growth factor; Plk: polo kinase; PKA: protein kinase A; PPase: protein phosphatase; SAS: spindle assembly abnormal; SPC: spindle pole body component; TRAPPI: transport protein particle I; wnt: Wingless integration; YFP: yellow fluorescent protein.

\section{Acknowledgements}

I thank current and former members of my laboratory for their help and discussions and Rick Heil-Chapdelaine for help with confocal imaging. I also acknowledge the support of my department. I apologize to those researchers whose work was not covered due to space limitations. I thank two anonymous reviewers for their time and efforts to improve this review.

\section{Authors' contributions}

CAL prepared the confocal microscopy specimens and carried out the literature research, sequence alignment and manuscript preparation.

\section{Competing interests}

The author declares that he has no competing interests.

Received: 3 February 2012 Accepted: 7 June 2012

Published: 7 June 2012

\section{References}

1. Wilson EB: The Cell in Development and Heredity New York: Macmillan; 1928.

2. Driever W, Stemple D, Schier A, Solnica-Krezel L: Zebrafish: genetic tools for studying vertebrate development. Trends Genet 1994, 10:152-159.

3. Trans-NIH Zebrafish Initiative. [http://www.nih.gov/science/models/ zebrafish/].

4. Andersen JS, Wilkinson CJ, Mayor T, Mortensen P, Nigg EA, Mann M: Proteomic characterization of the human centrosome by protein correlation profiling. Nature 2003, 426:570-574.

5. Nigg EA, Raff JW: Centrioles, centrosomes, and cilia in health and disease. Cell 2009, 139:663-678.

6. Gunawardane RN, Martin OC, Cao K, Zhang L, Dej K, Iwamatsu A, Zheng Y: Characterization and reconstitution of Drosophila $\gamma$-tubulin ring complex subunits. J Cell Biol 2000, 151:1513-1523.

7. Stearns T, Kirschner M: In vitro reconstitution of centrosome assembly and function: the central role of $\gamma$-tubulin. Cell 1994, 76:623-637.

8. Zheng $Y$, Wong ML, Alberts $B$, Mitchison T: Nucleation of microtubule assembly by a $\mathrm{\gamma}$-tubulin-containing ring complex. Nature 1995, 378:578-583.

9. Hannak E, Oegema K, Kirkham M, Gönczy P, Habermann B, Hyman AA: The kinetically dominant assembly pathway for centrosomal asters in Caenorhabditis elegans is $\gamma$-tubulin dependent. J Cell Biol 2002, 157:591-602

10. Schnorrer F, Luschnig S, Koch I, Nüsslein-Volhard C: $y$-Tubulin37C and $\gamma$ tubulin ring complex protein 75 are essential for bicoid RNA localization during Drosophila oogenesis. Dev Cell 2002, 3:685-696.

11. Choo S, Heinrich B, Betley JN, Chen Z, Deshler JO: Evidence for common machinery utilized by the early and late RNA localization pathways in Xenopus oocytes. Dev Biol 2005, 278:103-117.

12. Jesuthasan S: Furrow-associated microtubule arrays are required for the cohesion of zebrafish blastomeres following cytokinesis. J Cell Sci 1998, 111:3695-3703.

13. Lu Fl, Thisse C, Thisse B: Identification and mechanism of regulation of the zebrafish dorsal determinant. Proc Natl Acad Sci USA 2011, 108:15876-15880.

14. Evans L, Mitchison T, Kirschner M: Influence of the centrosome on the structure of nucleated microtubules. J Cell Biol 1985, 100:1185-1191.

15. Kobayashi T, Dynlacht BD: Regulating the transition from centriole to basal body. J Cell Biol 2011, 193:435-444. 
16. Pedersen LB, Veland IR, Schrøder JM, Christensen ST: Assembly of primary cilia. Dev Dyn 2008, 237:1993-2006.

17. Gerdes JM, Davis EE, Katsanis N: The vertebrate primary cilium in development, homeostasis, and disease. Cell 2009, 137:32-45.

18. Santos N, Reiter JF: Building it up and taking it down: the regulation of vertebrate ciliogenesis. Dev Dyn 2008, 237:1972-1981.

19. Azimzadeh J, Bornens M: Structure and duplication of the centrosome. $J$ Cell Sci 2007, 120:2139-2142.

20. Azimzadeh J, Bornens M: The centrosome in evolution. In Centrosomes in Development and Disease. Edited by: Nigg EA. Weinheim: Wiley-VCH Verlag GmbH 2004:93-122.

21. Bornens M, Azimzadeh J: Origin and evolution of the centrosome. In Eukaryotic Membranes and Cytoskeleton: Origins and Evolution. Edited by: Jékely G. Austin, TX: Landes Bioscience; 2007:119-129.

22. Rieder CL, Faruki S, Khodjakov A: The centrosome in vertebrates: more than a microtubule-organizing center. Trends Cell Biol 2001, 11:413-419.

23. Zyss D, Gergely F: Centrosome function in cancer: guilty or innocent? Trends Cell Biol 2009, 19:334-346.

24. Gould RR, Borisy GG: The pericentriolar material in Chinese hamster ovary cells nucleates microtubule formation. J Cell Biol 1977, 73:601-615.

25. Wilkinson CJ, Andersen JS, Mann M, Nigg EA: A proteomic approach to the inventory of the human centrosome. In Centrosomes in Development and Disease. Edited by: Nigg EA. Weinheim: Wiley-VCH Verlag GmbH 2004:123-142.

26. Kuriyama R: Activity and stability of centrosomes in Chinese hamster ovary cells in nucleation of microtubules in vitro. J Cell Sci 1984, 66:277-295.

27. Klotz C, Dabauvalle MC, Paintrand M, Weber T, Bornens M, Karsenti E: Parthenogenesis in Xenopus eggs requires centrosomal integrity. J Cell Biol 1990, 110:405-415.

28. Soltys BJ, Borisy GG: Polymerization of tubulin in vivo: direct evidence for assembly onto microtubule ends and from centrosomes. J Cell Biol 1985, 100:1682-1689.

29. Moritz M, Braunfeld MB, Sedat JW, Alberts B, Agard DA: Microtubule nucleation by $\gamma$-tubulin-containing rings in the centrosome. Nature 1995, 378:638-640

30. Oegema K, Wiese C, Martin OC, Milligan RA, Iwamatsu A, Mitchison TJ, Zheng Y: Characterization of two related Drosophila $y$-tubulin complexes that differ in their ability to nucleate microtubules. J Cell Biol 1999, 144:721-733.

31. Wiese $C$, Zheng $Y$ : $Y$-Tubulin complexes and their interaction with microtubule-organizing centers. Curr Opin Struct Biol 1999, 9:250-259.

32. Oakley CE, Oakley BR: Identification of $\gamma$-tubulin, a new member of the tubulin superfamily encoded by mipA gene of Aspergillus nidulans. Nature 1989, 338:662-664

33. Stearns T, Evans L, Kirschner M: $\gamma$-Tubulin is a highly conserved component of the centrosome. Cell 1991, 65:825-836.

34. Zheng Y, Jung MK, Oakley BR: $Y$-Tubulin is present in Drosophila melanogaster and Homo sapiens and is associated with the centrosome. Cell 1991, 65:817-823.

35. Dictenberg JB, Zimmerman W, Sparks CA, Young A, Vidair C, Zheng $Y$, Carrington W, Fay FS, Doxsey SJ: Pericentrin and $y$-tubulin form a protein complex and are organized into a novel lattice at the centrosome. J Cell Biol 1998, 141:163-174.

36. Doxsey SJ, Stein P, Evans L, Calarco PD, Kirschner M: Pericentrin, a highly conserved centrosome protein involved in microtubule organization. Cell 1994, 76:639-650.

37. Joshi HC: Microtubule organizing centers and $y$-tubulin. Curr Opin Cell Biol 1994, 6:54-62

38. Moritz $M$, Zheng $Y$, Alberts BM, Oegema $K$ : Recruitment of the $\gamma$-tubulin ring complex to Drosophila salt-stripped centrosome scaffolds. J Cell Biol $1998,142: 775-786$

39. Zimmerman WC, Sillibourne J, Rosa J, Doxsey SJ: Mitosis-specific anchoring of $\gamma$-tubulin complexes by pericentrin controls spindle organization and mitotic entry. Mol Biol Cell 2004, 15:3642-3657.

40. Joshi HC, Palacios MJ, MCNamara L, Cleveland DW: $Y$-Tubulin is a centrosomal protein required for cell cycle-dependent microtubule nucleation. Nature 1992, 356:80-83

41. Fuller SD, Gowen BE, Reinsch S, Sawyer A, Buendia B, Wepf R, Karsenti E: The core of the mammalian centriole contains y-tubulin. Curr Biol 1995, 5:1384-1393.
42. Ruiz F, Beisson J, Rossier J, Dupuis-Williams P: Basal body duplication in Paramecium requires Y-tubulin. Curr Biol 1999, 9:43-46.

43. Moudjou M, Bordes N, Paintrand M, Bornens M: $Y$-Tubulin in mammalian cells: the centrosomal and the cytosolic forms. J Cell Sci 1996, 109:875-887.

44. Daunderer C, Graf R: Molecular analysis of the cytosolic Dictyostelium Ytubulin complex. Eur J Cell Biol 2002, 81:175-184.

45. Oegema K, Whitfield WGF, Alberts B: The cell cycle-dependent localization of the CP190 centrosomal protein is determined by the coordinate action of two separable domains. J Cell Biol 1995, 131:1261-1273.

46. Khodjakov A, Rieder CL: The sudden recruitment of $\gamma$-tubulin to the centrosomes at the onset of mitosis and its dynamic exchange throughout the cell cycle, do not require microtubules. J Cell Biol 1999, 146:585-596.

47. Félix MA, Antony $C$, Wright $M$, Maro B: Centrosome assembly in vitro: role of $\gamma$-tubulin recruitment in Xenopus sperm aster formation. J Cell Biol 1994, 124:19-31.

48. Bobinnec Y, Fukuda M, Nishida E: Identification and characterization of Caenorhabditis elegans $\gamma$-tubulin in dividing cells and differentiated tissues. J Cell Sci 2000, 113:3747-3759.

49. Lajoie-Mazenc I, Tollon Y, Detraves C, Julian M, Moisand A, GuethHallonet C, Debec A, Salles-Passador I, Puget A, Mazarguil H, RaynaudMessina $B$, Wright $M$ : Recruitment of antigenic $\gamma$-tubulin during mitosis in animal cells: presence of $\gamma$-tubulin in the mitotic spindle. J Cell Sci 1994, 107:2825-2837.

50. Burns RG: $\alpha-, \beta-$, and $\gamma$-tubulins: Sequence comparisons and structural constraints. Cell Motil Cytoskeleton 1991, 20:181-189.

51. Burns RG: Analysis of the $\gamma$-tubulin sequences: implications for the functional properties of $y$-tubulin. J Cell Sci 1995, 108:2123-2130.

52. Tuszynski JA, Carpenter EJ, Huzil JT, Malinski W, Luchko T, Ludueña RF: The evolution of the structure of tubulin and its potential consequences for the role and function of microtubules in cells and embryos. Int J Dev Biol 2006, 50:341-358.

53. Liu J, Lessman CA: Soluble tubulin complexes, $\gamma$-tubulin, and their changing distribution in the zebrafish (Danio rerio) ovary, oocyte and embryo. Comp Biochem Physiol B Biochem Mol Biol 2007, 147:56-73.

54. Dekens MPS, Pelegri FJ, Maischein HM, Nüsslein-Volhard C: The maternaleffect gene futile cycle is essential for pronuclear congression and mitotic spindle assembly in the zebrafish zygote. Development 2003, 130:3907-3916

55. Julian M, Tollon Y, Lajoie-Mazenc I, Moisand A, Mazarguil H, Puget A, Wright $\mathrm{M}$ : $\gamma$-Tubulin participates in the formation of the midbody during cytokinesis in mammalian cells. J Cell Sci 1993, 105:145-156.

56. Schnackenberg BJ, Khodjakov A, Rieder CL, Palazzo RE: The disassembly and reassembly of functional centrosomes in vitro. Proc Natl Acad Sci USA 1998, 95:9295-9300.

57. Moritz M, Braunfeld MB, Guénebaut V, Heuser J, Agard DA: Structure of the $\gamma$-tubulin ring complex: a template for microtubule nucleation. Nat Cell Biol 2000, 2:365-370

58. Oegema K, Wiese C, Martin OC, Milligan RA, Iwamatsu A, Mitchison TJ, Zheng Y: Characterization of two related Drosophila $\mathrm{Y}$-tubulin complexes that differ in their ability to nucleate microtubules. J Cell Biol 1999, 144:721-733.

59. Kollman JM, Polka JK, Zelter A, Davis TN, Agard DA: Microtubule nucleating Y-TuSC assembles structures with 13-fold microtubule-like symmetry. Nature 2010, 466:879-882

60. Knop M, Schiebel E: Spc98p and Spc97p of the yeast $\gamma$-tubulin complex mediate binding to the spindle pole body via their interaction with Spc110p. EMBO J 1997, 16:6985-6995.

61. Murphy SM, Urbani L, Stearns T: The mammalian $\gamma$-tubulin complex contains homologues of the yeast spindle pole body components Spc97p and Spc98p. I Cell Biol 1998, 141:663-674.

62. Kane DA: Cell cycles and development in the embryonic zebrafish. Methods Cell Biol 1999, 59:11-26.

63. Kane DA, Kimmel CB: The zebrafish midblastula transition. Development 1993, 119:447-456

64. Liu J, Lessman CA: Changes of $\mathrm{y}$-tubulin expression and distribution in the zebrafish (Danio rerio) ovary, oocyte and embryo. Gene Expr Patterns 2008, 8:237-247.

65. Teixidó-Travesa N, Villén J, Lacasa C, Bertran MT, Archinti M, Gygi SP, Caelles C, Roig J, Lüders J: The YTuRC revisited: a comparative analysis of 
interphase and mitotic human $\mathrm{YTuRC}$ redefines the set of core components and identifies the novel subunit GCP8. Mol Biol Cell 2010, 21:3963-3972

66. Strnad P, Gönczy P: Mechanisms of procentriole formation. Trends Cell Biol 2008, 18:389-396.

67. Schatten $H$, Sun QY: The role of centrosomes in fertilization, cell division and establishment of asymmetry during embryo development. Semin Cell Dev Biol 2010, 21:174-184

68. Kitagawa D, Vakonakis I, Olieric N, Hilbert M, Keller D, Olieric V, Bortfeld M, Erat MC, Flückiger I, Gönczy P: Structural basis of the 9-fold symmetry of centrioles. Cell 2011, 144:364-375.

69. Gromley A, Jurczyk A, Sillibourne J, Halilovic E, Mogensen M, Groisman I, Blomberg M, Doxsey S: A novel human protein of the maternal centriole is required for the final stages of cytokinesis and entry into $\mathrm{S}$ phase. $J$ Cell Biol 2003, 161:535-545

70. In Centrosomes in Development and Disease. Edited by: Nigg EA. Weinheim, Germany: Wiley-VCH Verlag GmbH 2004:

71. Yabe T, Ge X, Pelegri F: The zebrafish maternal-effect gene cellular atoll encodes the centriolar component sas- 6 and defects in its paternal function promote whole genome duplication. Dev Biol 2007, 312:44-60.

72. Lindeman RE, Pelegri F: Vertebrate maternal-effect genes: insights into fertilization, early cleavage divisions, and germ cell determinant localization from studies in the zebrafish. Mol Reprod Dev 2010, 77:299-313.

73. Puklowski A, Homsi Y, Keller D, May M, Chauhan S, Kossatz U, Grünwald V, Kubicka S, Pich A, Manns MP: The SCF-Fbxw5 E3-ubiquitin ligase is regulated by Plk4 and targets HsSAS- 6 to control centrosome duplication. Nat Cell Biol 2011, 13:1004-1009.

74. van Breugel M, Hirono M, Andreeva A, Yanagisawa $H$, Yamaguchi S, Nakazawa Y, Morgner N, Petrovich M, Ebong IO, Robinson CV, Johnson CM, Veprintsev D, Zuber B: Structures of SAS-6 suggest its organization in centrioles. Science 2011, 331:1196-1199.

75. Dzhindzhev NS, Yu QD, Weiskopf K, Tzolovsky G, Cunha-Ferreira I, Riparbelli M, Rodrigues-Martins A, Bettencourt-Dias M, Callaini G, Glover DM: Asterless is a scaffold for the onset of centriole assembly. Nature 2010, 467:714-718.

76. Ikegami R, Hunter P, Yager TD: Developmental activation of the capability to undergo checkpoint-induced apoptosis in the early zebrafish embryo. Dev Biol 1999, 209:409-433.

77. Yabe T, Ge X, Lindeman R, Nair S, Runke G, Mullins MC, Pelegri F: The maternal-effect gene cellular island encodes aurora B kinase and is essential for furrow formation in the early zebrafish embryo. PLOS Genet 2009, 5:e1000518.

78. Vaughan S, Dawe HR: Common themes in centriole and centrosome movements. Trends Cell Biol 2011, 21:57-66.

79. Friedberg F: Centrin isoforms in mammals: relation to calmodulin. Mol Biol Rep 2006, 33:243-252.

80. Paoletti A, Moudjou M, Paintrand M, Salisbury JL, Bornens M: Most of centrin in animal cells is not centrosome-associated and centrosoma centrin is confined to the distal lumen of centrioles. J Cell Sci 1996, 109:3089-3202

81. Salisbury $J \mathrm{~L}$, Suino $K \mathrm{KM}_{\text {, Busby } R} \mathrm{R}$, Springett $M$ : Centrin-2 is required for centriole duplication in mammalian cells. Curr Biol 2002, 12:1287-1292.

82. White RA, Pan Z, Salisbury JL: GFP-centrin as a marker for centriole dynamics in living cells. Microsc Res Tech 2000, 49:451-457.

83. Piel M, Meyer $\mathrm{P}$, Khodjakov A, Rieder $\mathrm{CL}$, Bornens M: The respective contributions of the mother and daughter centrioles to centrosome activity and behavior in vertebrate cells. J Cell Biol 2000, 149:317-330.

84. Manandhar G, Feng D, Yi YJ, Lai L, Letko J, Laurincik J, Sutovsky M, Salisbury JL, Prather RS, Schatten H, Sutovsky P: Centrosomal protein centrin is not detectable during early pre-implantation development but reappears during late blastocyst stage in porcine embryos. Reproduction 2006, 132:423-434

85. Tourbez M, Firanescu C, Yang A, Unipan L, Duchambon P, Blouquit Y, Craescu CT: Calcium-dependent self-assembly of human centrin 2. J Biol Chem 2004, 279:47672-47680

86. Zamora I, Marshall WF: A mutation in the centriole-associated protein centrin causes genomic instability via increased chromosome loss in Chlamydomonas reinhardtii. BMC Biol 2005, 3:15

87. Lutz W, Lingle WL, McCormick D, Greenwood TM, Salisbury JL: Phosphorylation of centrin during the cell cycle and its role in centriole separation preceding centrosome duplication. J Biol Chem 2001, 276:20774-20780.

88. Trojan P, Krauss N, Choe HW, GießI A, Pulvermüller A, Wolfrum U: Centrins in retinal photoreceptor cells: regulators in the connecting cilium. Prog Retin Eye Res 2008, 27:237-259.

89. Distel M, Hocking JC, Volkmann K, Köster RW: The centrosome neither persistently leads migration nor determines the site of axonogenesis in migrating neurons in vivo. J Cell Biol 2010, 191:875-890.

90. Zolessi FR, Poggi L, Wilkinson CJ, Chien CB, Harris WA: Polarization and orientation of retinal ganglion cells in vivo. Neural Dev 2006, 1:2

91. Norden C, Young S, Link BA, Harris WA: Actomyosin is the main driver of interkinetic nuclear migration in the retina. Cell 2009, 138:1195-1208.

92. Higginbotham H, Bielas S, Tanaka T, Gleeson JG: Transgenic mouse line with green-fluorescent protein-labeled Centrin 2 allows visualization of the centrosome in living cells. Transgenic Res 2004, 13:155-164.

93. Schoppmeier J, Mages W, Lechtreck KF: GFP as a tool for the analysis of proteins in the flagellar basal apparatus of Chlamydomonas. Cell Motil Cytoskeleton 2005, 61:189-200.

94. Flory MR, Moser MJ, Monnat RJ Jr, Davis TN: Identification of a human centrosomal calmodulin-binding protein that shares homology with pericentrin. Proc Natl Acad Sci USA 2000, 97:5919-5923.

95. Flory MR, Davis TN: The centrosomal proteins pericentrin and kendrin are encoded by alternatively spliced products of one gene. Genomics 2003, 82:401-405.

96. Miyoshi K, Asanuma M, Miyazaki I, Matsuzaki S, Tohyama M, Ogawa N: Characterization of pericentrin isoforms in vivo. Biochem Biophys Res Commun 2006, 351:745-749.

97. Delaval B, Doxsey SJ: Pericentrin in cellular function and disease. J Cell Biol 2010, 188:181-190.

98. Wang Z, Wu T, Shi L, Zhang L, Zheng W, Qu JY, Niu R, Qi RZ: Conserved motif of CDK5RAP2 mediates its localization to centrosomes and the Golgi complex. J Biol Chem 2010, 285:22658-22665.

99. Michaud EJ, Yoder BK: The primary cilium in cell signaling and cancer. Cancer Res 2006, 66:6463-6467.

100. Rohatgi R, Snell WJ: The ciliary membrane. Curr Opin Cell Biol 2010 22:541-546.

101. Satir P, Christensen ST: Structure and function of mammalian cilia. Histochem Cell Biol 2008, 129:687-693.

102. Veland IR, Awan A, Pedersen LB, Yoder BK, Christensen ST: Primary cilia and signaling pathways in mammalian development, health and disease. Nephron Physiol 2009, 111:p39-p53.

103. Rohatgi R, Milenkovic L, Scott MP: Patched1 regulates hedgehog signaling at the primary cilium. Science 2007, 317:372-376.

104. Goetz SC, Anderson KV: The primary cilium: a signalling centre during vertebrate development. Nat Rev Genet 2010, 11:331-344.

105. Borovina A, Superina S, Voskas D, Ciruna B: Vangl2 directs the posterior tilting and asymmetric localization of motile primary cilia. Nat Cell Biol 2010, 12:407-412.

106. Corbit KC, Aanstad P, Singla V, Norman AR, Stainier DYR, Reiter JF: Vertebrate Smoothened functions at the primary cilium. Nature 2005, 437:1018-1021

107. Ingham PW, Kim HR: Hedgehog signalling and the specification of muscle cell identity in the zebrafish embryo. Exp Cell Res 2005, 306:336-342.

108. Huang P, Schier AF: Dampened Hedgehog signaling but normal Wnt signaling in zebrafish without cilia. Development 2009, 136:3089-3098.

109. Clément A, Solnica-Krezel L, Gould KL: The Cdc14B phosphatase contributes to ciliogenesis in zebrafish. Development 2011, 138:291-302.

110. Kim S, Zaghloul NA, Bubenshchikova E, Oh EC, Rankin S, Katsanis N, Obara T, Tsiokas L: Nde1-mediated inhibition of ciliogenesis affects cell cycle re-entry. Nat Cell Biol 2011, 13:351-360.

111. Lopes CAM, Prosser SL, Romio L, Hirst RA, O'Callaghan C, Woolf AS, Fry AM: Centriolar satellites are assembly points for proteins implicated in human ciliopathies, including oral-facial-digital syndrome 1. J Cell Sci 2011, 124:600-612.

112. Pathak N, Obara T, Mangos S, Liu Y, Drummond IA: The zebrafish fleer gene encodes an essential regulator of cilia tubulin polyglutamylation. Mol Biol Cell 2007, 18:4353-4364.

113. Moorman SJ, Shimada N, Sokunbi G, Pfirrmann C: Simulated-microgravity induced changes in gene expression in zebrafish embryos suggest that 
the primary cilium is involved in gravity transduction. Gravit Space Biol 2007, 1089:79-86.

114. Moorman SJ, Shorr AZ: The primary cilium as a gravitational force transducer and a regulator of transcriptional noise. Dev Dyn 2008, 237:1955-1959.

115. Neugebauer JM, Amack JD, Peterson AG, Bisgrove BW, Yost HJ: FGF signaling during embryo development regulates cilia length in diverse epithelia. Nature 2009, 458:651-654.

116. Baye LM, Patrinostro X, Swaminathan S, Beck JS, Zhang Y, Stone EM Sheffield VC, Slusarski DC: The N-terminal region of centrosomal protein 290 (CEP290) restores vision in a zebrafish model of human blindness. Hum Mol Genet 2011, 20:1467-1477.

117. Bachmann-Gagescu R, Phelps IG, Stearns G, Link BA, Brockerhoff SE, Moens $C B$, Doherty D: The ciliopathy gene cc2d2a controls zebrafish photoreceptor outer segment development through a role in Rab8dependent vesicle trafficking. Hum Mol Genet 2011, 20:4041-4055.

118. Glazer AM, Wilkinson AW, Backer CB, Lapan SW, Gutzman JH, Cheeseman IM, Reddien PW: The Zn finger protein lguana impacts Hedgehog signaling by promoting ciliogenesis. Dev Biol 2010, 337:148-156.

119. Huang S, Ma J, Liu X, Zhang Y, Luo L: Geminin is required for left-right patterning through regulating Kupffer's vesicle formation and ciliogenesis in zebrafish. Biochem Biophys Res Commun 2011, 410:164-169.

120. Swanhart LM, Cosentino CC, Diep CQ, Davidson AJ, de Caestecker M, Hukriede NA: Zebrafish kidney development: basic science to translational research. Birth Defects Res C Embryo Today 2011, 93:141-156.

121. Westlake CJ, Baye LM, Nachury MV, Wright K, Ervin KE, Phu L, Chalouni C, Beck JS, Kirkpatrick DS, Slusarski DC, Sheffield VC, Scheller RH, Jackson PK: Primary cilia membrane assembly is initiated by Rab11 and transport protein particle II (TRAPPII) complex-dependent trafficking of Rabin8 to the centrosome. Proc Natl Acad Sci USA 2011, 108:2759-2764.

122. Wilkinson C, Carl M, Harris W: Cep70 and Cep131 contribute to ciliogenesis in zebrafish embryos. BMC Cell Biol 2009, 10:17.

123. Wilson CW, Nguyen CT, Chen MH, Yang JH, Gacayan R, Huang J, Chen JN Chuang PT: Fused has evolved divergent roles in vertebrate Hedgehog signalling and motile ciliogenesis. Nature 2009, 459:98-102.

124. Wloga D, Webster DM, Rogowski K, Bré MH, Levilliers N, Jerka-Dziadosz M, Janke C, Dougan ST, Gaertig J: TTLL3 is a tubulin glycine ligase that regulates the assembly of cilia. Dev Cell 2009, 16:867-876.

125. Duldulao NA, Lee S, Sun Z: Cilia localization is essential for in vivo functions of the Joubert syndrome protein Arl13b/Scorpion. Development 2009, 136:4033-4042.

126. Walsh GS, Grant PK, Morgan JA, Moens CB: Planar polarity pathway and Nance-Horan syndrome-like $1 \mathrm{~b}$ have essential cell-autonomous functions in neuronal migration. Development 2011, 138:3033-3042.

127. Lessman CA: The developing zebrafish (Danio rerio): a vertebrate model for high-throughput screening of chemical libraries. Birth Defects Res $C$ Embryo Today 2011, 93:268-280

doi:10.1186/2046-2530-1-9

Cite this article as: Lessman: Centrosomes in the zebrafish (Danio rerio): a review including the related basal body. Cilia 2012 1:9.

\section{Submit your next manuscript to BioMed Central and take full advantage of:}

- Convenient online submission

- Thorough peer review

- No space constraints or color figure charges

- Immediate publication on acceptance

- Inclusion in PubMed, CAS, Scopus and Google Scholar

- Research which is freely available for redistribution

Submit your manuscript at www.biomedcentral.com/submit
Ciomed Central 